\title{
Predictors of physical activity change during adolescence: a 3.5-year follow-up
}

\author{
Samuel C Dumith ${ }^{1, *}+$, Denise P Gigante ${ }^{1}$, Marlos R Domingues ${ }^{1}$, Pedro C Hallal ${ }^{1}$, \\ Ana MB Menezes ${ }^{1}$ and Harold W Kohl III' \\ ${ }^{1}$ Postgraduate Program in Epidemiology, Federal University of Pelotas, Pelotas, Brazil: ${ }^{2}$ Michael and Susan Dell \\ Center for Advancement of Healthy Living, University of Texas Health Science Center - Houston, Huston, TX, and \\ School of Public Health, Austin Regional Campus and Department of Kinesiology and Health Education, \\ University of Texas at Austin, Austin, TX, USA
}

Submitted 10 September 2011: Final revision received 20 January 2012: Accepted 24 February 2012: First published online 11 0ctober 2012

\begin{abstract}
Objective: To investigate the predictors of change in physical activity (PA) from early to mid adolescence in a cohort of adolescents.

Design: Prospective, population-based birth cohort study. PA level was evaluated by means of questionnaire, and was analysed in continuous form (min/week) and as a trajectory (inactive-inactive, inactive-active, active-inactive, active-active) based on the cut-off point of $300 \mathrm{~min} /$ week.

Setting: Pelotas, a city of 340000 inhabitants in southern Brazil.

Subjects: Adolescents ( $n$ 4120) followed from 11 to 15 years of age.

Results: Maternal PA change and more exposure to outdoors were directly associated with a positive change in PA level (min/week) for both genders. Higher maturation status (among boys) and later menarche were also associated with positive PA change in $\mathrm{min} /$ week. Predictors to remain inactive were: maternal PA change (inverse association), more exposure to outdoors, higher socio-economic level, fear of living in the neighbourhood and non-overweight girls. Predictors to become inactive were higher socio-economic level among boys and increase in screen time among girls. Conclusions: The study demonstrates that social, family, biological, behavioural and environmental factors exert an important role in the PA change among youngsters as they move into adolescence. These findings may be relevant to the design of policies and intervention programmes aimed at promoting PA in teenagers.
\end{abstract}

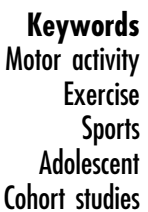

Physical inactivity levels are rising in many countries with major implications for the prevalence of non-communicable diseases and the general health of populations worldwide ${ }^{(1)}$. The health benefits of physical activity (PA) are widely demonstrated by the recent scientific literature ${ }^{(2)}$. There is strong evidence that, even among children and adolescents, regular PA improves body composition, cardiorespiratory and muscular fitness, bone health and metabolic health biomarkers $^{(2)}$. Moreover, PA during youth can exert both direct and indirect positive effects on adult health ${ }^{(3)}$ and PA levels track from childhood/adolescence to adulthood ${ }^{(4)}$, suggesting that PA promotion must start early in life ${ }^{(5)}$.

Nevertheless, there is evidence demonstrating that PA levels decline during adolescence ${ }^{(6,7)}$. However, the determinants of PA change in this age group are not well known. Although some review papers have summarized the factors associated with PA among adolescents ${ }^{(8-11)}$, most original studies included in these reviews have been

$\dagger$ Correspondence address: Marechal Deodoro 1160, 3rd floor, 96020-220 Pelotas, RS, Brasil. cross-sectional, restricting the evidence to correlates (associated factors without an evidence of temporality) rather than to predictors (determinants) of $\mathrm{PA}^{(12)}$. Furthermore, the determinant of a behaviour does not mean the same as a determinant of behaviour change ${ }^{(13)}$.

We did not find any study in a low- or middle-income country providing prospective data on PA change and its predictors among adolescents. Even in high-income countries there are few studies with that approach, making it hard to build a level of scientific evidence. Therefore, the aim of the present study was to investigate the predictors of PA change from early to mid adolescence in a birth cohort from a developing country.

\section{Methods}

\section{Study design and population}

We used data from a longitudinal prospective study, conducted among participants of the 1993 Pelotas (Brazil) Birth Cohort Study. This cohort comprises all children 
born in the calendar year of 1993 ( $n$ 5249) in Pelotas, a city of 340000 inhabitants in southern Brazil. In 2004, when they were on average 11 years old (mean 11.3 (sD $0 \cdot 3$ ) years), all participants were sought for a new follow-up, and 4452 members (87.5\%) of the original cohort were traced. In 2008, when they were 14 to 15 years of age (referred to herein as ' 15 years'; mean $14 \cdot 7$ $(\mathrm{SD} 0.3)$ years), all individuals were sought again, and 4325 were followed $(85 \cdot 2 \%)$. Overall, 4120 adolescents ( $81 \cdot 3 \%$ of the original cohort, discounting the 147 deaths known) had complete information regarding PA for both waves (11 and 15 years). There was no difference in terms of PA levels (min/week) between those who were interviewed in both periods and those who were not found in the last survey in 2008 ( $n$ 199; $P=0 \cdot 98$ ). Moreover, the profile of individuals included in the present study and the original cohort was similar in terms of socio-economic, demographic and anthropometric variables.

Average follow-up duration was 3.4 (SD 0.2) years, ranging from $2 \cdot 8$ to $4 \cdot 0$ years. Detailed information about the cohort methodology and previous follow-ups are published elsewhere ${ }^{(14-16)}$. The study protocol was approved by the Ethics Committee of the Medical School from the Federal University of Pelotas, and the parents or guardians of all participants signed a written informed consent.

\section{Logistics and instrument}

Each data collection period (2004 and 2008) lasted approximately 8 months. The first one was carried out from July 2004 to March 2005; whereas the second wave extended from January to August 2008. The methodology employed in both surveys was the same. Data were collected by trained interviewers through face-to-face home interviews. A standardized and previously tested questionnaire was used ${ }^{(17)}$. One questionnaire was administered to mothers (or guardians) and another, with different questions, to the adolescent. Measurements of weight, height and subscapular and triceps skinfold thickness were collected in both waves. Skinfold thicknesses were measured using a Cescorf scientific calliper (Porto Alegre, Brazil), following the recommendations of Lohman et al. ${ }^{(18)}$. Weight and height were obtained using respectively a SECA digital scale (Birmingham, UK) with $100 \mathrm{~g}$ precision and an aluminium stadiometer (Seca) with $1 \mathrm{~mm}$ precision.

For quality control purposes, $30 \%$ of the participants were re-interviewed (10\% in person, $20 \%$ by telephone call), using a short questionnaire, by two study supervisors. The agreement between the first and the second interviews was $100 \%$ for all variables. Additionally, all questionnaires were checked for completeness and consistency by study supervisors, once they were completed.

\section{Outcome}

The outcome analysed in the present study was the change in PA status. This variable was constructed based on selfreport data, administered by face-to-face interviews. The instrument included moderate-to-vigorous physical activities performed in leisure time (outdoor and indoor soccer, volleyball, basketball, handball, athletics, dance, swimming, gymnastic, tennis, martial arts). For each PA, the adolescent was queried if he/she engaged in it in the previous $7 \mathrm{~d}$, and if so, how many times per week (d/week) and for how long $(\mathrm{min} / \mathrm{d})$.

A very similar version of the instrument was administered in both waves. The only difference was the replacement of two physical activities more common in childhood (outside games) by activities that are more common in mid-adolescence (walking for recreation and weight lifting). Additionally, the interviewer asked if the adolescent was also engaged in another type of PA that was not cited in the questionnaire. More than one could be reported and they were also coded and further analysed. The questionnaire did not include questions regarding physical education classes, although other types of organized activities performed in school could be mentioned.

A score in minutes per week ( $\mathrm{min} /$ week) was derived for each type of PA, multiplying its duration ( $\mathrm{min} / \mathrm{d}$ ) by its frequency (d/week). Further, an overall score of PA in $\mathrm{min} /$ week was generated by the sum of all single scores. We decided to not weight PA estimates by the metabolic equivalent, because it can vary between individuals, even for the same activity.

\section{Predictors}

The variables included as possible predictors of PA change were: (i) self-reported skin colour (white, mixed, black); (ii) socio-economic level at baseline, an index generated by principal component analysis of nineteen assets in the household ${ }^{(14)}$ and categorized into tertiles (poorest, intermediate, wealthiest); (iii) maternal leisure-time PA change between both waves, self-reported by questionnaire in terms of duration (min) and frequency (d), and divided into four groups (always zero, decreased, increased $<150 \mathrm{~min} /$ week, increased $\geq 150 \mathrm{~min} /$ week); (iv) amount of time spent outdoors in comparison with peers, selfreported by the adolescent at baseline (mostly indoors, mostly outdoors); (v) pattern of fear of living in the neighbourhood from 11 to 15 years (never, no longer, developed, always); (vi) BMI status at 11 years, based on objective measurement of weight, height, triceps and subscapular skinfold thicknesses, and classified according to the cut-off points proposed by $\mathrm{WHO}^{(19)}$ (underweight or normal, overweight, obese); (vii) sexual maturation at 15 years, based on Tanner's stages ${ }^{(20)}$ (divided into quartiles) among boys and on the age of menarche (dichotomized by 12 years and over) among girls; and (viii) screen time change between 11 and 15 years, which consisted of time spent watching television, playing video games or using a computer, divided into tertiles of the weekly time difference from 15 years minus 11 years (lowest - decreased; intermediate - increased up to $2 \mathrm{~h}$ /week; highest - increased more than $2 \mathrm{~h} /$ week). 


\section{Statistical analyses}

Data were double entered by two data-entry clerks and then analysed using the STATA statistical software package version 10 (StataCorp, College Station, TX, USA). The outcome was analysed in two ways: (i) the change in the PA level expressed in min/week (continuous variable), which corresponds to the PA score of 15 years old minus the PA score of 11 years old; and (ii) PA level was dichotomized according to the $300 \mathrm{~min} /$ week threshold ${ }^{(2,21)}$ and then its trajectory was analysed in four groups based on PA category at 11 and 15 years, namely inactive-inactive, inactive-active, active-inactive and active-active.

For analysis of the change in PA level, a multiple linear regression was used. Two models were run: Model 1, with adjustment for baseline PA level (min/week at 11 years) and follow-up duration (in months); and Model 2, with a further adjustment for the co-predictors. The adjusted mean change (min/week) rather than the $\beta$ coefficients are presented in the tables as a means of ease of interpretation. It was not necessary to transform the outcome, because the PA change distribution was close to normality. For PA trajectory analysis, Poisson regression with robust variance was used. Two cohorts were generated according to the PA category at baseline: inactive or active. Then, the groups of interest were those who remained inactive for the inactive cohort (reference group: those who became active) and those who became inactive for the active cohort (reference group: those who remained active). For both the unadjusted and adjusted analyses, the relative risks (RR) along with the 95\% confidence intervals are presented.

The adjusted analyses (both for the continuous and categorical change) followed a five-level hierarchical model $^{(22)}$. On the first level, there were skin colour and socio-economic level; on the second, maternal PA; on the third, time spent outdoors and fear of the neighbourhood; on the fourth, BMI at baseline and sexual maturation; and on the last level, screen time change. Each variable was adjusted for those of the same or upper levels (e.g. BMI was controlled for sexual maturation and those variables of first, second and third levels). All analyses were stratified by gender, and statistical tests were two-sided with a significance level of $5 \%(P<0 \cdot 05)$.

\section{Results}

Out of the 4120 adolescents, 51\% were female, $66 \%$ had white skin colour and $24 \%$ were overweight or obese at 11 years. Two-thirds of adolescents' mothers were not involved with leisure-time PA in both waves and $4 \cdot 2 \%$ were physically active ( $\geq 150 \mathrm{~min} /$ week) in the two waves. Twentyseven per cent of the adolescents were exposed mostly outdoors compared with their peers, and $75 \%$ reported no fear of living in their neighbourhood throughout the followup. Most girls (69\%) had their menarche before 12 years.

In the entire sample PA level increased on average by $15(95 \% \mathrm{CI}-4,35) \mathrm{min} /$ week, from an average of $341 \mathrm{~min} /$ week at 11 years to $356 \mathrm{~min} /$ week at 15 years. Specifically, among boys it increased by an average of 75 (95\% CI 49, 100) $\mathrm{min} /$ week from $436 \mathrm{~min} /$ week at 11 years to $511 \mathrm{~min} /$ week at 15 years; while among girls it decreased by an average of $42(95 \% \mathrm{CI}-57,-28) \mathrm{min} /$ week from $249 \mathrm{~min} /$ week to $207 \mathrm{~min} /$ week. PA level at 11 and 15 years presented a weak correlation $(\rho=0 \cdot 22)$ that was similar among boys $(\rho=0 \cdot 16)$ and girls $(\rho=0 \cdot 14)$. Figure 1 illustrates the median change in PA level according to the PA trajectory from 11 to 15 years of age. According to the $300 \mathrm{~min} /$ week threshold, $62.7 \%$ of the study participants were inactive at baseline $(52 \cdot 3 \%$ of boys and $72 \cdot 8 \%$ of girls). Of those, most (68\%) remained physically inactive during the follow-up (Fig. 1). Of those who were active at

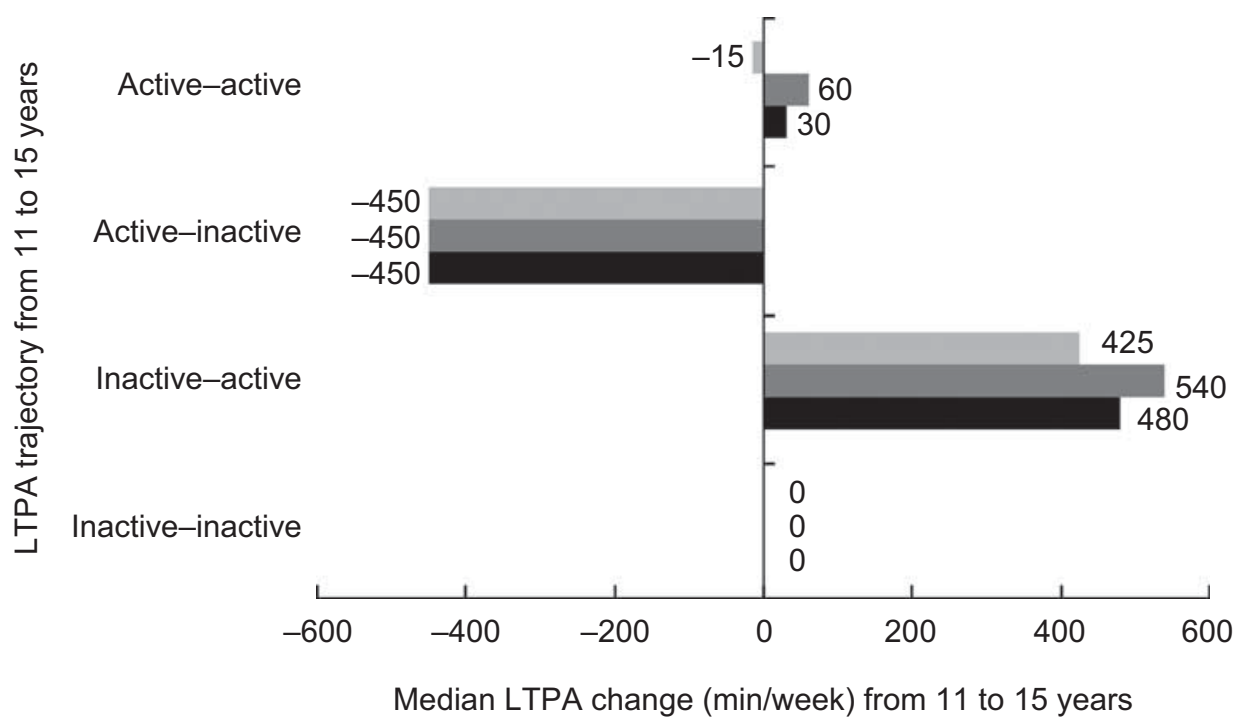

Fig. 1 Median change in leisure-time physical activity (LTPA; min/week) from 11 to 15 years according to physical activity trajectory and sex (, girls; $\square$, boys; $\mathbf{\square}$, all); 1993 Pelotas (Brazil) Birth Cohort Study ( $n$ 4120), 2004-2008 


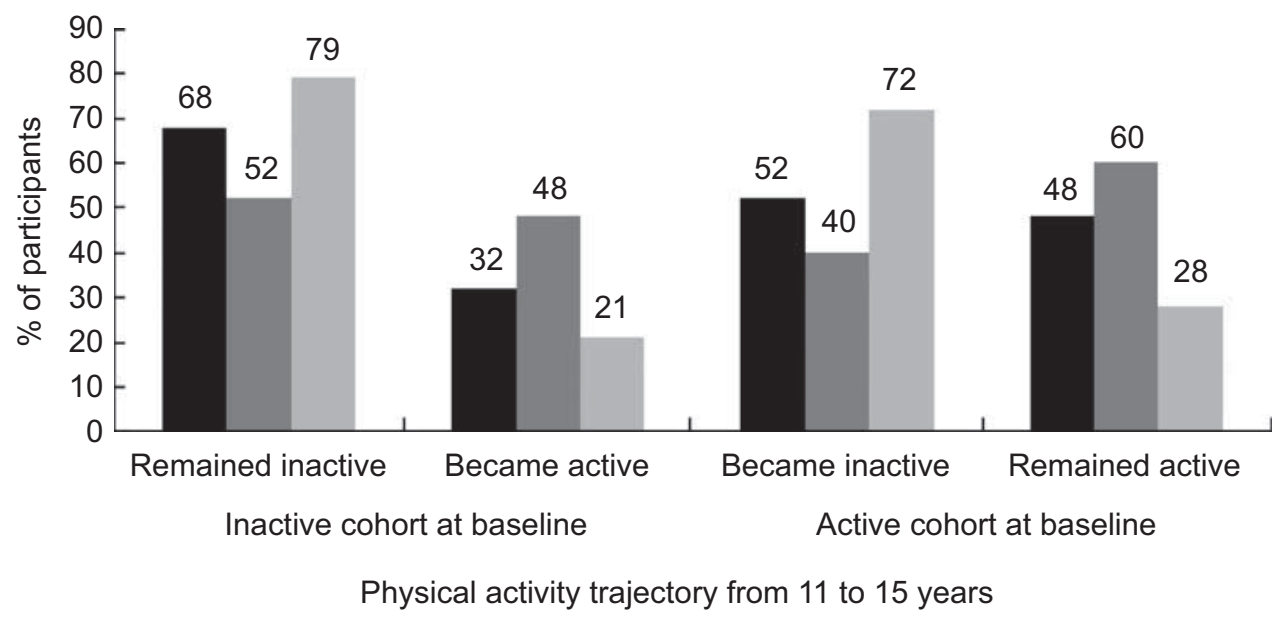

Fig. 2 Physical activity trajectory from 11 to 15 years according to sex ( $($, girls; $\square$, boys; $\mathbf{\square}$, all); 1993 Pelotas (Brazil) Birth Cohort Study, 2004-2008 (n 4120)

11 years $(37 \cdot 3 \%)$, many girls $(72 \%)$ became inactive, while most boys (60\%) remained active (Fig. 2).

The predictors of PA change (min/week) stratified by gender are shown in Table 1. According to Model 1 (adjustment only for baseline PA level and follow-up duration), non-white participants showed a significantly lower increase among boys and a higher decrease among girls. PA increase among boys was inversely associated with socio-economic level, although there were no differences among girls. Maternal leisure-time PA change between both waves was directly associated with PA change in both boys and girls. Those with mostly outdoors exposure presented a greater positive change compared with those who spent more time indoors. Neither fear of living in the neighbourhood nor BMI at 11 years was associated with PA change. Maturation among boys was directly associated to PA levels. Among girls, those who had menarche earlier tended to decrease their PA level more. Change in screen time between 11 and 15 years was not associated with PA change. When further adjustment for the other covariates was performed, most associations were unchanged. The only differences were that skin colour was no longer associated with PA change and age of menarche reached statistical significance.

Examining PA trajectory, the predictors of remaining inactive in the inactive cohort (reference group: those who became active during the follow-up) can be seen in Table 2 . Among boys, the variables associated with a higher risk to remain inactive in the unadjusted analyses were higher socio-economic level $(\mathrm{RR}=1 \cdot 17$; 95\% CI $1 \cdot 01,1 \cdot 35)$ and fear of living in the neighbourhood $(\mathrm{RR}=1 \cdot 45$; $95 \%$ CI $1 \cdot 19$, 1.78). Maternal PA increase $\geq 150 \mathrm{~min} /$ week $(\mathrm{RR}=0 \cdot 77$; 95\% CI 0.61, 0.97) and mostly outdoors exposure while growing up ( $\mathrm{RR}=0 \cdot 76 ; 95 \% \mathrm{CI} 0 \cdot 65,0 \cdot 89)$ were protective factors to remain inactive. Among girls, those whose maternal PA increased $\geq 150 \mathrm{~min} /$ week $(\mathrm{RR}=0 \cdot 85 ; 95 \% \mathrm{CI}$ $0 \cdot 76,0 \cdot 92$ ), who were mostly outdoors while growing up
$(\mathrm{RR}=0 \cdot 89 ; 95 \% \mathrm{CI} 0 \cdot 83,0 \cdot 96)$ or were obese at 11 years $(\mathrm{RR}=0 \cdot 89 ; 95 \% \mathrm{CI} 0 \cdot 80,0.99)$ were at a lower risk to remain inactive. Results were similar in the adjusted analyses.

The predictors of becoming inactive in the active cohort (reference group: those who remained active during the follow-up) are presented in Table 3. Only socio-economic level (among boys) and screen time change (among girls) were associated (directly) with the risk to become inactive, even after the adjusted analyses.

\section{Discussion}

To our knowledge, the present study is the first one to address predictors of PA change in a cohort of adolescents from a developing country. Even in developed countries, very few longitudinal studies so far have focused on this issue, and the results are not consistent. To investigate the predictors of PA change, two different approaches were employed. First, we analysed the change in the level of PA (in min/week) from 11 to 15 years; second, we assessed the PA trajectory, by dividing our sample in two sub-cohorts (inactive or active at baseline) to investigate the predictors to either remain or become inactive.

Skin colour was associated with change in PA level, but lost its statistical significance after adjustment for socioeconomic level. Two other studies also did not find association in the PA change between white and non-white adolescents $^{(23,24)}$. However, another longitudinal study showed that the decline in PA over adolescence was higher among black than white girls ${ }^{(25)}$. Despite this, the classification of skin colour may vary significantly across countries. With respect to socio-economic level, two studies from the $\mathrm{USA}^{(24,25)}$ and one from Norway ${ }^{(26)}$ showed that the PA decline was higher among those with lower family income or whose parents had lower schooling level. In our study, socio-economic level did not predict PA change in girls but 
Table 1 Change in leisure-time physical activity (LTPA; min/week) from 11 to 15 years according to potential predictors; 1993 Pelotas (Brazil) birth Cohort Study, 2004-2008 ( $n$ 4120)

\begin{tabular}{|c|c|c|c|c|c|c|c|c|c|c|c|c|c|c|}
\hline \multirow[b]{3}{*}{ Predictor } & \multicolumn{8}{|c|}{ Model $1^{*}$} & \multicolumn{6}{|c|}{ Model 2† } \\
\hline & \multicolumn{4}{|c|}{ Boys } & \multicolumn{4}{|c|}{ Girls } & \multicolumn{3}{|c|}{ Boys } & \multicolumn{3}{|c|}{ Girls } \\
\hline & $n$ & Mean & $95 \% \mathrm{Cl}$ & $P$ value & $n$ & Mean & $95 \% \mathrm{Cl}$ & $P$ value & Mean & $95 \% \mathrm{Cl}$ & $P$ value & Mean & $95 \% \mathrm{Cl}$ & $P$ value \\
\hline Skin colour & & & & 0.01 & & & & 0.04 & & & 0.08 & & & 0.09 \\
\hline White & 1301 & 51 & 19,82 & & 1334 & -60 & $-77,-42$ & & 55 & 23,88 & & -59 & $-77,-41$ & \\
\hline Mixed & 344 & 131 & 69,193 & & 391 & -14 & $-47,19$ & & 112 & 49,175 & & -15 & $-50,19$ & \\
\hline Black & 296 & 143 & 76,210 & & 297 & -32 & $-70,5$ & & 132 & 62,201 & & -47 & $-86,-8$ & \\
\hline Socio-economic level & & & & $<0.01 \ddagger$ & & & & $0 \cdot 25 \ddagger$ & & & $0.01 \ddagger$ & & & $0.54 \ddagger$ \\
\hline Poorest & 668 & 121 & 77,165 & & 645 & -36 & $-62,-10$ & & 124 & 78,169 & & -46 & $-73,-20$ & \\
\hline Intermediate & 622 & 75 & 30,121 & & 707 & -43 & $-67,-18$ & & 77 & 30,124 & & -43 & $-68,-19$ & \\
\hline Wealthiest & 670 & 24 & $-17,71$ & & 668 & -57 & $-83,-32$ & & 30 & $-16,76$ & & -58 & $-84,-32$ & \\
\hline Mother's LTPA change & & & & $0.02 \ddagger$ & & & & $0.01 \ddagger$ & & & $<0.01 \ddagger$ & & & $<0.01 \ddagger$ \\
\hline Always zero & 1366 & 56 & 25,87 & & 1404 & -51 & $-69,-33$ & & 48 & 15,81 & & -62 & $-81,-44$ & \\
\hline Decreased & 303 & 77 & 11,143 & & 337 & -51 & $-87,-14$ & & 85 & 17,154 & & -47 & $-84,-10$ & \\
\hline Increased $<150 \mathrm{~min} /$ week & 170 & 143 & 55,231 & & 172 & -26 & $-78,26$ & & 169 & 79,259 & & -26 & $-78,25$ & \\
\hline Increased $\geq 150 \mathrm{~min} /$ week & 227 & 135 & 58,211 & & 237 & 12 & $-32,55$ & & 156 & 77,234 & & 15 & $-29,59$ & \\
\hline Exposure during growing-up & & & & 0.05 & & & & $<0.01$ & & & 0.04 & & & 0.01 \\
\hline Mostly indoors & 1399 & 59 & 28,89 & & 1631 & -55 & $-71,-38$ & & 59 & 27,91 & & -59 & $-75,-42$ & \\
\hline Mostly outdoors & 617 & 114 & 68,160 & & 462 & 3 & $-28,34$ & & 119 & 70,167 & & -9 & $-41,22$ & \\
\hline Fear of living in neighbourhood & & & & 0.87 & & & & 0.06 & & & 0.92 & & & 0.24 \\
\hline Never & 1604 & 74 & 46,103 & & 1481 & -55 & $-72,-37$ & & 77 & 48,107 & & -57 & $-75,-40$ & \\
\hline No longer & 216 & 95 & 18,173 & & 247 & -24 & $-66,18$ & & 90 & 9,171 & & -20 & $-63,23$ & \\
\hline Developed & 128 & 41 & $-60,142$ & & 239 & -17 & $-60,25$ & & 45 & $-62,152$ & & -36 & $-80,7$ & \\
\hline Always & 68 & 77 & $-61,216$ & & 127 & 14 & $-44,72$ & & 94 & $-57,244$ & & -13 & $-74,47$ & \\
\hline BMI status at 11 years & & & & $0.48 \ddagger$ & & & & $0 \cdot 11 \ddagger$ & & & $0.76 \ddagger$ & & & $0 \cdot 10 \ddagger$ \\
\hline Normal & 1510 & 77 & 48,107 & & 1636 & -47 & $-63,-30$ & & 89 & 51,127 & & -49 & $-66,-32$ & \\
\hline Overweight & 199 & 105 & 24,186 & & 276 & -47 & $-86,-7$ & & 138 & 41,236 & & -36 & $-79,6$ & \\
\hline Obese & 313 & 43 & $-21,108$ & & 181 & 3 & $-46,52$ & & 93 & 16,170 & & -2 & $-55,50$ & \\
\hline Sexual maturation in quartiles & & & & $0.02 \ddagger$ & & & & & & & $<0.01 \ddagger$ & & & \\
\hline 1 (least) & 494 & 61 & 10,111 & & - & - & - & & 48 & $-5,101$ & & - & - & \\
\hline 2 & 380 & 91 & 33,148 & & - & - & - & & 95 & 36,155 & & - & - & \\
\hline 3 & 258 & 81 & 12,151 & & - & - & - & & 98 & 24,171 & & - & - & \\
\hline 4 (most) & 200 & 197 & 117,276 & & - & - & - & & 212 & 128,297 & & - & - & \\
\hline Age of menarche & & & & & & & & 0.07 & & & & & & 0.04 \\
\hline Before 12 years & - & - & - & & 616 & -61 & $-88,-35$ & & - & - & & -71 & $-99,-45$ & \\
\hline 12 years or older & - & - & - & & 1397 & -32 & $-50,-14$ & & - & - & & -36 & $-54,-18$ & \\
\hline Screen time change in tertiles & & & & $0 \cdot 11 \ddagger$ & & & & $0 \cdot 70 \ddagger$ & & & $0 \cdot 22 \ddagger$ & & & $0.55 \ddagger$ \\
\hline Least & 630 & 44 & $-1,89$ & & 751 & -34 & $-58,-10$ & & 61 & 2,120 & & -40 & $-65,-14$ & \\
\hline Intermediate & 647 & 84 & 39,129 & & 730 & -65 & $-89,-40$ & & 110 & 53,167 & & -70 & $-95,-45$ & \\
\hline Highest & 729 & 95 & 52,137 & & 613 & -24 & $-51,3$ & & 112 & 59,165 & & -26 & $-53,2$ & \\
\hline Total & 2023 & 75 & 49,100 & & 2097 & -42 & $-57,-28$ & & 96 & 64,128 & & -43 & $-58,-28$ & \\
\hline
\end{tabular}

${ }^{*}$ Adjusted for baseline PA level (min/week) and follow-up duration (months).

tAdjusted as in Model 1 plus predictors in the same level or the levels above.

$\ddagger P$ value for linear trend.

presented an inverse association among boys. Additionally, the wealthiest boys were more likely to either remain inactive or become inactive, compared with boys in the lowest tertile of socio-economic level. We hypothesize this may be an effect of the sedentary behaviour more common among the wealthiest boys than the poorest ones.

Importantly, maternal PA change was the characteristic most associated with adolescent PA change in our study. Girls whose mothers' PA increased $\geq 150 \mathrm{~min} /$ week during the follow-up were the only group of girls to show an increase in PA level, although non-significant (mean 15 (95\% CI $-29,59) \mathrm{min} /$ week). In a linear regression analyses, including in the model maternal PA level as a continuous variable and adjusting for mother's and adolescent's PA at baseline and follow-up duration, we observed that for each increase of $1 \mathrm{~h} /$ week in mother's activity between both waves, there was an increase of $11 \mathrm{~min} /$ week $(95 \%$ CI 5, 17) in the adolescent's activity.

We located only one longitudinal study that investigated maternal PA as a predictor of PA change in adolescents, but no association was detected ${ }^{(27)}$. However, those authors examined the baseline level and not the change in mother's activity as we did here. In an additional analysis (data not shown), we observed that maternal PA level at baseline did not predict the adolescent's PA change. Moreover, inactive 11-year-olds whose mothers increased their PA level $\geq 150 \mathrm{~min} /$ week throughout the study were more likely to become active at the age of 15 years. Nevertheless, it is worth mentioning that maternal PA change was not a predictor of PA trajectory among the adolescents who were already active at baseline. This finding suggests that maternal behaviour seems to exert a positive influence on PA profile among those adolescents who are inactive, but does not appear to affect those who are already active from early to mid adolescence.

Outdoors exposure was also highly associated with PA change. Adolescents who grew up mostly outdoors were less likely to remain inactive during the follow-up. The variable fear of living in the neighbourhood was not a predictor of PA change (min/week), but presented an 
Table 2 Unadjusted and adjusted relative risk (RR) of remaining inactive (compared with those who became active) from 11 to 15 years, according to the examined predictors (in the inactive cohort at 11 years); 1993 Pelotas (Brazil) birth Cohort Study, 2004-2008

\begin{tabular}{|c|c|c|c|c|c|c|c|c|c|c|c|c|}
\hline \multirow[b]{3}{*}{ Predictor } & \multicolumn{6}{|c|}{ Unadjusted analyses } & \multicolumn{6}{|c|}{ Adjusted analyses } \\
\hline & \multicolumn{3}{|c|}{ Boys ( $n$ 1058) } & \multicolumn{3}{|c|}{ Girls ( $n$ 1527) } & \multicolumn{3}{|c|}{ Boys (n 965) } & \multicolumn{3}{|c|}{ Girls ( $n$ 570) } \\
\hline & $\mathrm{RR}$ & $95 \% \mathrm{Cl}$ & $P$ value & $\mathrm{RR}$ & $95 \% \mathrm{Cl}$ & $P$ value & $\mathrm{RR}$ & $95 \% \mathrm{Cl}$ & $P$ value & $\mathrm{RR}$ & $95 \% \mathrm{Cl}$ & $P$ value \\
\hline Skin colour & & & 0.04 & & & 0.68 & & & 0.08 & & & 0.83 \\
\hline White & $1 \cdot 00$ & Ref. & & $1 \cdot 00$ & Ref. & & $1 \cdot 00$ & Ref. & & $1 \cdot 00$ & Ref. & \\
\hline Mixed & 0.98 & $0 \cdot 84,1 \cdot 15$ & & 0.99 & $0.92,1.06$ & & $1 \cdot 01$ & $0 \cdot 86,1 \cdot 19$ & & 0.99 & $0.92,1.06$ & \\
\hline Black & 0.75 & $0.60,0.94$ & & 0.97 & $0.90,1.05$ & & 0.77 & $0.62,0.97$ & & 0.98 & $0.90,1.06$ & \\
\hline Socio-economic level & & & $0.04^{\star}$ & & & $0 \cdot 68^{*}$ & & & $0 \cdot 05^{\star}$ & & & $0 \cdot 63^{*}$ \\
\hline Poorest & $1 \cdot 00$ & Ref. & & $1 \cdot 00$ & Ref. & & $1 \cdot 00$ & Ref. & & $1 \cdot 00$ & Ref. & \\
\hline Intermediate & $1 \cdot 07$ & $0 \cdot 92,1 \cdot 25$ & & 0.97 & $0.92,1.04$ & & $1 \cdot 08$ & $0 \cdot 93,1 \cdot 27$ & & 0.97 & $0.90,1.03$ & \\
\hline Wealthiest & $1 \cdot 17$ & $1 \cdot 01,1 \cdot 35$ & & 0.99 & $0.93,1.05$ & & $1 \cdot 16$ & $1 \cdot 00,1 \cdot 35$ & & 0.98 & $0.92,1.05$ & \\
\hline Mother's LTPA change & & & $0 \cdot 01^{*}$ & & & $<0.01^{*}$ & & & $<0.01^{\star}$ & & & $<0.01^{*}$ \\
\hline Always zero & $1 \cdot 00$ & Ref. & & $1 \cdot 00$ & Ref. & & $1 \cdot 00$ & Ref. & & $1 \cdot 00$ & Ref. & \\
\hline Decreased & $0 \cdot 85$ & $0 \cdot 70,1 \cdot 03$ & & 0.98 & $0.91,1.05$ & & $0 \cdot 81$ & $0 \cdot 67,0.98$ & & 0.96 & $0 \cdot 89,1 \cdot 04$ & \\
\hline Increased $<150 \mathrm{~min} /$ week & 0.93 & $0 \cdot 75,1 \cdot 14$ & & 0.91 & $0.81,1.02$ & & $0 \cdot 86$ & $0.69,1.07$ & & 0.90 & $0 \cdot 81,1 \cdot 02$ & \\
\hline Increased $\geq 150 \mathrm{~min} /$ week & $0 \cdot 77$ & $0.61,0.96$ & & 0.85 & $0.76,0.92$ & & $0 \cdot 73$ & $0.58,0.92$ & & 0.83 & $0 \cdot 75,0.93$ & \\
\hline Exposure during growing up & & & $<0.01$ & & & $<0.01$ & & & $<0.01$ & & & $<0.01$ \\
\hline Mostly indoors & $1 \cdot 00$ & Ref. & & $1 \cdot 00$ & Ref. & & $1 \cdot 00$ & Ref. & & $1 \cdot 00$ & Ref. & \\
\hline Mostly outdoors & $0 \cdot 76$ & $0 \cdot 65,0 \cdot 89$ & & $0 \cdot 89$ & $0.83,0.96$ & & $0 \cdot 73$ & $0 \cdot 62,0.85$ & & 0.89 & $0.82,0.96$ & \\
\hline Fear of living in the neighbourhood & & & $<0.01$ & & & 0.53 & & & $<0.01$ & & & 0.59 \\
\hline Never & $1 \cdot 00$ & Ref. & & $1 \cdot 00$ & Ref. & & $1 \cdot 00$ & Ref. & & $1 \cdot 00$ & Ref. & \\
\hline No longer & 0.91 & $0 \cdot 73,1 \cdot 12$ & & 0.97 & $0.89,1.05$ & & 0.91 & $0 \cdot 74,1 \cdot 13$ & & 0.94 & $0 \cdot 86,1 \cdot 04$ & \\
\hline Developed & 0.92 & $0 \cdot 72,1 \cdot 17$ & & 0.94 & $0.86,1.03$ & & $0 \cdot 88$ & $0 \cdot 68,1 \cdot 13$ & & 0.97 & $0.89,1.05$ & \\
\hline Always & $1 \cdot 45$ & $1 \cdot 19,1 \cdot 78$ & & 0.98 & $0 \cdot 87,1 \cdot 10$ & & $1 \cdot 44$ & $1 \cdot 15,1 \cdot 79$ & & 0.98 & $0 \cdot 88,1 \cdot 10$ & \\
\hline BMI status at 11 years & & & $0 \cdot 78^{*}$ & & & $0 \cdot 04^{*}$ & & & $0 \cdot 88^{*}$ & & & $0 \cdot 01^{*}$ \\
\hline Normal & $1 \cdot 00$ & Ref. & & $1 \cdot 00$ & Ref. & & $1 \cdot 00$ & Ref. & & $1 \cdot 00$ & Ref. & \\
\hline Overweight & 0.97 & $0 \cdot 79,1 \cdot 18$ & & 0.98 & $0.90,1.05$ & & 0.95 & $0 \cdot 75,1 \cdot 22$ & & 0.96 & $0 \cdot 88,1 \cdot 05$ & \\
\hline Obese & $1 \cdot 03$ & $0 \cdot 88,1 \cdot 21$ & & $0 \cdot 89$ & $0.80,0.99$ & & 0.99 & $0 \cdot 81,1 \cdot 22$ & & 0.87 & $0.77,0.98$ & \\
\hline Sexual maturation in quartiles & & & $0 \cdot 26^{*}$ & & & & & & $0 \cdot 24^{*}$ & & & \\
\hline 1 (least) & $1 \cdot 00$ & Ref. & & - & - & & $1 \cdot 00$ & Ref. & & - & - & \\
\hline 2 & 0.99 & $0 \cdot 83,1 \cdot 18$ & & - & - & & $1 \cdot 00$ & $0 \cdot 84,1 \cdot 20$ & & - & - & \\
\hline 3 & 0.94 & $0 \cdot 76,1 \cdot 15$ & & - & - & & $0 \cdot 88$ & $0 \cdot 71,1 \cdot 09$ & & - & - & \\
\hline 4 (most) & 0.88 & $0 \cdot 69,1 \cdot 12$ & & - & - & & 0.90 & $0 \cdot 72,1 \cdot 16$ & & - & - & \\
\hline Age of menarche & & & & & & 0.53 & & & & & & $0 \cdot 17$ \\
\hline Before 12 years & - & - & & $1 \cdot 00$ & Ref. & & - & - & & $1 \cdot 00$ & Ref. & \\
\hline 12 years or older & - & - & & 0.98 & $0.93,1.04$ & & - & - & & 0.96 & $0.91,1.01$ & \\
\hline Screen time change in tertiles & & & $0 \cdot 16^{*}$ & & & $0 \cdot 33^{*}$ & & & $0 \cdot 22^{*}$ & & & $0 \cdot 23^{\star}$ \\
\hline Least & $1 \cdot 00$ & Ref. & & $1 \cdot 00$ & Ref. & & $1 \cdot 00$ & Ref. & & $1 \cdot 00$ & Ref. & \\
\hline Intermediate & 0.97 & $0 \cdot 84,1 \cdot 11$ & & $1 \cdot 06$ & $1 \cdot 00,1 \cdot 13$ & & 0.95 & $0 \cdot 78,1 \cdot 14$ & & $1 \cdot 06$ & $1 \cdot 00,1 \cdot 13$ & \\
\hline Highest & 0.90 & $0.78,1.04$ & & 0.96 & $0.90,1.03$ & & $0 \cdot 89$ & $0 \cdot 74,1 \cdot 07$ & & 0.95 & $0.88,1.02$ & \\
\hline
\end{tabular}

LTPA, leisure-time physical activity; Ref., referent category.

${ }^{\star} P$ value for linear trend.

interesting association with PA trajectory. Boys, but not girls, who were afraid to live in their neighbourhood were at higher risk (almost 50\%) to remain inactive over the follow-up, compared with those who had no fear, even after adjustment for potential confounders. We could not compare these findings with the literature because studies investigating the role of environmental variables (specifically, outdoors exposure and fear of living in the neighbourhood) on the PA change in adolescents were not found.

BMI status at baseline was not associated with change in PA level (min/week), but was a predictor of PA trajectory among girls. Girls who were obese at 11 years of age presented a lower risk to remain inactive compared with those who were neither obese nor overweight. This result may indicate that girls can improve their PA profile because they are not satisfied with their body. This finding, however, is not in agreement with others. In one study, baseline BMI presented a direct association with PA decline in girls ${ }^{(25)}$; the same finding was observed for BMI change in another study ${ }^{(28)}$. In a different investigation, girls who became overweight decreased their
PA level more than those who were no longer overweight $^{(29)}$. The results of a further study showed that overweight adolescents presented higher risk to remain inactive (less than one PA session daily), but not to decline their PA level ${ }^{(30)}$. In our study, overweight boys presented a 27 (95\% CI 1, 59) \% higher risk to become inactive, although it was no longer significant in the adjusted analyses. Two studies found no association between these variables $^{(27,31)}$.

Patterns of association between maturation status and PA change differed between boys and girls. While more mature boys presented a higher increase in PA level (min/week), among girls who were more mature the decline was higher, even after adjustment for confounders. The same associations were not verified in the PA trajectory analyses. However, the association between maturation status and PA change is not well established in the literature and more research is needed. We found three studies showing that: more mature boys declined their PA level more ${ }^{(32)}$, different from our results; more mature girls at 11 years had lower PA levels at 13 years ${ }^{(33)}$, consistent with 
Table 3 Unadjusted and adjusted relative risk of becoming inactive (compared with those who remained active) from 11 to 15 years, according to the examined predictors (in the active cohort at 11 years); 1993 Pelotas (Brazil) birth Cohort Study, 2004-2008

\begin{tabular}{|c|c|c|c|c|c|c|c|c|c|c|c|c|}
\hline \multirow[b]{3}{*}{ Predictor } & \multicolumn{6}{|c|}{ Unadjusted analyses } & \multicolumn{6}{|c|}{ Adjusted analyses } \\
\hline & \multicolumn{3}{|c|}{ Boys ( $n$ 1058) } & \multicolumn{3}{|c|}{ Girls (n 1527) } & \multicolumn{3}{|c|}{ Boys ( $n$ 965) } & \multicolumn{3}{|c|}{ Girls (n 570) } \\
\hline & $\mathrm{RR}$ & $95 \% \mathrm{Cl}$ & $P$ value & $\mathrm{RR}$ & $95 \% \mathrm{Cl}$ & $P$ value & $\mathrm{RR}$ & $95 \% \mathrm{Cl}$ & $P$ value & $\mathrm{RR}$ & $95 \% \mathrm{Cl}$ & $P$ value \\
\hline Skin colour & & & 0.21 & & & 0.42 & & & 0.49 & & & 0.56 \\
\hline White & $1 \cdot 00$ & Ref. & & $1 \cdot 00$ & Ref. & & $1 \cdot 00$ & Ref. & & $1 \cdot 00$ & Ref. & \\
\hline Mixed & $0 \cdot 84$ & $0.67,1.05$ & & 0.95 & $0.83,1.07$ & & $0 \cdot 88$ & $0 \cdot 70,1 \cdot 11$ & & 0.97 & $0 \cdot 84,1 \cdot 10$ & \\
\hline Black & 0.88 & $0 \cdot 71,1 \cdot 10$ & & 0.91 & $0.78,1.08$ & & 0.92 & $0.73,1 \cdot 17$ & & 0.92 & $0.79,1.08$ & \\
\hline Socio-economic level & & & $0.02^{*}$ & & & $0 \cdot 17^{\star}$ & & & $0.04^{\star}$ & & & $0 \cdot 42^{*}$ \\
\hline Poorest & $1 \cdot 00$ & Ref. & & $1 \cdot 00$ & Ref. & & $1 \cdot 00$ & Ref. & & $1 \cdot 00$ & Ref. & \\
\hline Intermediate & $1 \cdot 07$ & $0 \cdot 87,1 \cdot 31$ & & $1 \cdot 02$ & $0 \cdot 90,1 \cdot 16$ & & $1 \cdot 08$ & $0 \cdot 87,1 \cdot 33$ & & $1 \cdot 00$ & $0.90,1 \cdot 16$ & \\
\hline Wealthiest & $1 \cdot 26$ & $1.04,1.52$ & & 1.09 & $0.96,1.23$ & & $1 \cdot 23$ & $1 \cdot 01,1 \cdot 50$ & & 1.05 & $0.93,1.20$ & \\
\hline Mother's LTPA change & & & $0 \cdot 89^{*}$ & & & $0 \cdot 84^{*}$ & & & $0 \cdot 70^{\star}$ & & & $0 \cdot 54^{*}$ \\
\hline Always zero & $1 \cdot 00$ & Ref. & & $1 \cdot 00$ & Ref. & & $1 \cdot 00$ & Ref. & & $1 \cdot 00$ & Ref. & \\
\hline Decreased & 0.99 & $0 \cdot 80,1 \cdot 23$ & & 0.97 & $0 \cdot 84,1 \cdot 12$ & & 0.97 & $0.77,1 \cdot 21$ & & 0.96 & $0 \cdot 82,1 \cdot 11$ & \\
\hline Increased $<150 \mathrm{~min} /$ week & 0.90 & $0.66,1.23$ & & $1 \cdot 14$ & $0.99,1.31$ & & 0.83 & $0.60,1 \cdot 15$ & & 1.09 & $0.95,1.26$ & \\
\hline Increased $\geq 150 \mathrm{~min} /$ week & $1 \cdot 06$ & $0 \cdot 84,1 \cdot 35$ & & 0.93 & $0 \cdot 77,1 \cdot 11$ & & $1 \cdot 01$ & $0 \cdot 79,1 \cdot 30$ & & 0.90 & $0.75,1.09$ & \\
\hline Exposure during growing-up & & & 0.87 & & & $0 \cdot 19$ & & & 0.99 & & & $0 \cdot 25$ \\
\hline Mostly indoors & $1 \cdot 00$ & Ref. & & $1 \cdot 00$ & Ref. & & $1 \cdot 00$ & Ref. & & $1 \cdot 00$ & Ref. & \\
\hline Mostly outdoors & $1 \cdot 01$ & $0.91,1 \cdot 12$ & & 0.92 & $0.82,1.04$ & & $1 \cdot 00$ & $0 \cdot 84,1 \cdot 19$ & & 0.93 & $0.83,1.05$ & \\
\hline Fear of living in neighborhood & & & 0.97 & & & $0 \cdot 13$ & & & 0.89 & & & 0.32 \\
\hline Never & $1 \cdot 00$ & Ref. & & $1 \cdot 00$ & Ref. & & $1 \cdot 00$ & Ref. & & $1 \cdot 00$ & Ref. & \\
\hline No longer & 0.95 & $0 \cdot 74,1 \cdot 23$ & & 0.85 & $0.71,1.02$ & & 0.93 & $0 \cdot 71,1 \cdot 22$ & & 0.84 & $0.69,1.02$ & \\
\hline Developed & 0.94 & $0.66,1.36$ & & 0.97 & $0 \cdot 82,1 \cdot 14$ & & 0.91 & $0.62,1.35$ & & 0.98 & $0 \cdot 83,1 \cdot 14$ & \\
\hline Always & $1 \cdot 01$ & $0.66,1.55$ & & 0.82 & $0.64,1.04$ & & $1 \cdot 09$ & $0.71,1.67$ & & 0.94 & $0 \cdot 65,1 \cdot 16$ & \\
\hline BMI status at 11 years & & & $0 \cdot 79^{\star}$ & & & $0.63^{*}$ & & & $0.96^{*}$ & & & $0 \cdot 56^{*}$ \\
\hline Normal & $1 \cdot 00$ & Ref. & & $1 \cdot 00$ & Ref. & & $1 \cdot 00$ & Ref. & & $1 \cdot 00$ & Ref. & \\
\hline Overweight & $1 \cdot 27$ & $1.01,1.59$ & & $1 \cdot 11$ & $0.97,1.27$ & & $1 \cdot 23$ & $0.91,1.65$ & & $1 \cdot 10$ & $0.96,1.26$ & \\
\hline Obese & 0.97 & $0.78,1.22$ & & 0.98 & $0.80,1 \cdot 20$ & & 0.96 & $0 \cdot 73,1 \cdot 25$ & & 1.00 & $0 \cdot 81,1 \cdot 24$ & \\
\hline Sexual maturation in quartiles & & & $0 \cdot 21^{*}$ & & & & & & $0.08^{*}$ & & & \\
\hline 1 (least) & $1 \cdot 00$ & Ref. & & - & - & & $1 \cdot 00$ & Ref. & & - & - & \\
\hline 2 & 0.98 & $0 \cdot 77,1 \cdot 24$ & & - & - & & 0.92 & $0 \cdot 72,1 \cdot 17$ & & - & - & \\
\hline 3 & 0.91 & $0.69,1.20$ & & - & - & & 0.87 & $0.65,1 \cdot 16$ & & - & - & \\
\hline 4 (most) & 0.83 & $0 \cdot 61,1 \cdot 14$ & & - & - & & 0.75 & $0.53,1.05$ & & - & - & \\
\hline Age of menarche & & & & & & $0 \cdot 10$ & & & & & & $0 \cdot 17$ \\
\hline Before 12 years & - & - & & $1 \cdot 00$ & Ref. & & - & - & & $1 \cdot 00$ & Ref. & \\
\hline 12 years or older & - & - & & 0.91 & $0 \cdot 82,1 \cdot 02$ & & - & - & & 0.93 & $0.83,1.03$ & \\
\hline Screen time change in tertiles & & & $0 \cdot 75^{\star}$ & & & $0.04^{*}$ & & & $0 \cdot 39^{\star}$ & & & $0 \cdot 01^{*}$ \\
\hline Least & $1 \cdot 00$ & Ref. & & $1 \cdot 00$ & Ref. & & $1 \cdot 00$ & Ref. & & $1 \cdot 00$ & Ref. & \\
\hline Intermediate & $0 \cdot 82$ & $0.67,1.00$ & & 1.07 & $0.94,1 \cdot 21$ & & 0.83 & $0.63,1.09$ & & 1.09 & $0.95,1 \cdot 24$ & \\
\hline Highest & $1 \cdot 02$ & $0 \cdot 86,1 \cdot 22$ & & $1 \cdot 14$ & $1 \cdot 00,1 \cdot 29$ & & $1 \cdot 10$ & $0.86,1.39$ & & $1 \cdot 18$ & $1 \cdot 04,1 \cdot 34$ & \\
\hline
\end{tabular}

LTPA, leisure-time physical activity; Ref., referent category.

${ }^{\star} P$ value for linear trend.

our findings; and maturation status is not associated with PA change in adolescents ${ }^{(31)}$.

Change in screen time, defined by the time spent watching television, playing video games or using a computer, was not associated with PA change level (min/week), but presented a direct association with the risk of becoming inactive among girls who were active at baseline. This effect in girls was mainly due to an increase in the time spent watching television, rather than using a computer or playing video games (data not shown). Again, the literature findings are not consistent on this association. We identified three studies showing an inverse association between screen time and PA change ${ }^{(30,34,35)}$, which was more marked among girls and mainly due to an increase in time spent watching television. On the other hand, in two studies there was no association between screen time and PA change in adolescents $^{(36,37)}$, which suggests that they may be independent behaviours rather than complementary.

Among the strengths of our study, we highlight: (i) that our conclusions are based on a population-based sample of adolescents; (ii) the low attrition rate between the waves $(7 \cdot 5 \%)$ and the high response rate considering the original cohort $(85 \cdot 2 \%)$; (iii) the investigation of many variables that can affect PA behaviour; and (iv) the use of different analytical approaches to examine the predictors of PA change.

Some methodological limitations should also be mentioned. First, although the instrument used was basically the same in both waves, its understanding could be different by boys and girls at 11 and 15 years old. However, if this happened, we believe that it occurred in the same way for every individual at each age, not resulting in systematic bias. To reinforce that argument, another study compared the PA change by self-report (questionnaire) and objective measurement (accelerometer) in adolescents over 3 years, and did not find any difference in the PA decline during this period ${ }^{(38)}$. Second, sexual maturation in boys was collected only at 15 years, and did not allow assessment of the effect of maturation status at baseline. Nevertheless, as this variable was categorized according to the development of their peers rather than an absolute cut-off point, we think that it was not a drawback. Third, the $300 \mathrm{~min} /$ week 
threshold used to classify the individuals as active or inactive, although supported by the literature ${ }^{(2,21)}$, could imply in some misclassification errors. Nevertheless, we did some simulations employing two different cut-off points to classify the PA level (210 min/week and $420 \mathrm{~min} /$ week) and the findings were very similar (data not shown). Besides, analysing trajectories with the use of categorical variables makes it easier to interpret our findings and discuss them in the context of current physical activity guidelines for adolescents. Lastly, it would also be interesting to evaluate the effect of paternal PA on the adolescent's activity change. However, such a variable was not collected at the 11 years wave.

The present study has some practical implications. It demonstrated the influence of maternal behaviour regarding PA and the effect of the environment on PA change in adolescence. Other studies have shown that social support (from family or peers) can affect PA in adolescents ${ }^{(32,39)}$. Therefore, stimulating parental PA, promoting more outdoor activities, and improving the neighbourhood safety and available leisure-time facilities may contribute to increasing (or minimizing the decline of) PA during youth. These findings are important in terms of policies and intervention programmes for PA behaviour in children and adolescents. Among girls, the reduction in sedentary time, particularly the time spent watching television, also can attenuate the PA decline during adolescence. Different from developed countries, more attention should be paid to boys from higher socio-economic level. Thereby, more studies are needed to build solid evidence on the predictors of PA change in adolescents, which may differ according to the setting under investigation.

\section{Acknowledgements}

This study was supported by the Wellcome Trust initiative entitled 'Major Awards for Latin America on Health Consequences of Population Change' (process 072403/Z/03/Z). S.C.D. received scholarships from the National Council of Technological and Scientific Development (CNPq; process 142187/2007-0) and from the Brazilian Federal Agency for Support and Evaluation of Graduate Education (CAPES; process 4273/08-7). The funding agencies had no participation in the interpretation, analysis, writing and approval of this manuscript. The authors have no other potential conflicts of interest. S.C.D. conceived the study, conducted the analyses and wrote a first draft. D.P.G., M.R.D., P.C.H., A.M.B.M. and H.W.K. contributed to the interpretation of data and critically reviewed the manuscript. All authors approved the final version of the paper.

\section{References}

1. World Health Organization (2010) Global Recommendations on Physical Activity for Health. Geneva: WHO.
2. US Department of Health and Human Services (2008) Physical Activity Guidelines Advisory Committee Report 2008. Washington, DC: DHHS.

3. Twisk JW, Kemper HC \& van Mechelen W (2002) Prediction of cardiovascular disease risk factors later in life by physical activity and physical fitness in youth: general comments and conclusions. Int J Sports Med 23, 44-49.

4. Telama R, Yang X, Viikari J et al. (2005) Physical activity from childhood to adulthood: a 21 -year tracking study. $\mathrm{Am}$ J Prev Med 28, 267-273.

5. Hallal PC, Victora CG, Azevedo MR et al. (2006) Adolescent physical activity and health: a systematic review. Sports Med 36, 1019-1030.

6. Dumith SC, Gigante DP, Domingues MR et al. (2011) Physical activity change during adolescence: a systematic review and a pooled analysis. Int J Epidemiol 40, 685-698.

7. Sallis JF (2000) Age-related decline in physical activity: a synthesis of human and animal studies. Med Sci Sports Exerc 32, 1598-1600.

8. Ferreira I, van der Horst K, Wendel-Vos W et al. (2007) Environmental correlates of physical activity in youth - a review and update. Obes Rev 8, 129-154.

9. Sallis JF, Prochaska JJ \& Taylor WC (2000) A review of correlates of physical activity of children and adolescents. Med Sci Sports Exerc 32, 963-975.

10. Seabra AF, Mendonca DM, Thomis MA et al. (2008) Biological and socio-cultural determinants of physical activity in adolescents. Cad Saude Publica 24, 721-736.

11. Van Der Horst K, Paw MJ, Twisk JW et al. (2007) A brief review on correlates of physical activity and sedentariness in youth. Med Sci Sports Exerc 39, 1241-1250.

12. Bauman AE, Sallis JF, Dzewaltowski DA et al. (2002) Toward a better understanding of the influences on physical activity: the role of determinants, correlates, causal variables, mediators, moderators, and confounders. Am J Prev Med 23, 5-14.

13. Brug J, Oenema A \& Ferreira I (2005) Theory, evidence and intervention mapping to improve behavior nutrition and physical activity interventions. Int J Behav Nutr Phys Act 2, 2.

14. Araujo CL, Menezes AM, Vieira MF et al. (2010) The 11-year follow-up of the 1993 Pelotas (Brazil) birth cohort study: methods. Cad Saude Publica 26, 1875-1886.

15. Victora CG, Araujo CL, Menezes AM et al. (2006) Methodological aspects of the 1993 Pelotas (Brazil) Birth Cohort Study. Rev Saude Publica 40, 39-46.

16. Victora CG, Hallal PC, Araujo CL et al. (2008) Cohort profile: the 1993 Pelotas (Brazil) birth cohort study. Int J Epidemiol 37, 704-709.

17. Hallal PC, Wells JC, Reichert FF et al. (2006) Early determinants of physical activity in adolescence: prospective birth cohort study. BMJ 32, 1002-1005.

18. Lohman TG, Roche AF \& Martorell R (1988) Anthropometric Standardization Reference Manual. Champaign, IL: Human Kinetics.

19. World Health Organization (1995) Expert Committee on Physical Status: The Use and Interpretation of Anthropometry. Geneva: WHO.

20. Tanner JM (1962) Growth at Adolescence. Oxford: Blackwell.

21. Strong WB, Malina RM, Blimkie CJ et al. (2005) Evidence based physical activity for school-age youth. J Pediatr 146, $732-737$.

22. Victora CG, Huttly SR, Fuchs SC et al. (1997) The role of conceptual frameworks in epidemiological analysis: a hierarchical approach. Int J Epidemiol 26, 224-227.

23. Garcia AW, Pender NJ, Antonakos CL et al. (1998) Changes in physical activity beliefs and behaviors of boys and girls across the transition to junior high school. J Adolesc Health 22, 394-402. 
24. Nader PR, Bradley RH, Houts RM et al. (2008) Moderate-tovigorous physical activity from ages 9 to 15 years. JAMA 300, 295-305.

25. Kimm SY, Glynn NW, Kriska AM et al. (2002) Decline in physical activity in black girls and white girls during adolescence. $N$ Engl J Med 347, 709-715.

26. Sagatun A, Kolle E, Anderssen SA et al. (2008) Three-year follow-up of physical activity in Norwegian youth from two ethnic groups: associations with socio-demographic factors. BMC Public Health 8, 419.

27. Kahn JA, Huang B, Gillman MW et al. (2008) Patterns and determinants of physical activity in US adolescents. $J$ Adolesc Health 42, 369-377.

28. Raudsepp L \& Viira R (2008) Changes in physical activity in adolescent girls: a latent growth modelling approach. Acta Paediatr 97, 647-652.

29. McMurray RG, Harrell JS, Creighton D et al. (2008) Influence of physical activity on change in weight status as children become adolescents. Int J Pediatr Obes $\mathbf{3}$, 69-77.

30. Barnett TA, O'Loughlin J \& Paradis G (2002) One- and twoyear predictors of decline in physical activity among innercity schoolchildren. Am J Prev Med 23, 121-128.

31. Knowles AM, Niven AG, Fawkner SG et al. (2009) A longitudinal examination of the influence of maturation on physical self-perceptions and the relationship with physical activity in early adolescent girls. J Adolesc 32, 555-566.
32. Duncan SC, Duncan TE, Strycker LA et al. (2007) A cohortsequential latent growth model of physical activity from ages 12 to 17 years. Ann Behav Med 33, 80-89.

33. Baker BL, Birch LL, Trost SG et al. (2007) Advanced pubertal status at age 11 and lower physical activity in adolescent girls. J Pediatr 151, 488-493.

34. Motl RW, McAuley E, Birnbaum AS et al. (2006) Naturally occurring changes in time spent watching television are inversely related to frequency of physical activity during early adolescence. J Adolesc 29, 19-32.

35. Raudsepp L, Neissaar I \& Kull M (2008) Longitudinal stability of sedentary behaviors and physical activity during early adolescence. Pediatr Exerc Sci 20, 251-262.

36. Robinson TN, Hammer LD, Killen JD et al. (1993) Does television viewing increase obesity and reduce physical activity? Cross-sectional and longitudinal analyses among adolescent girls. Pediatrics 91, 273-280.

37. Taveras EM, Field AE, Berkey CS et al. (2007) Longitudinal relationship between television viewing and leisure-time physical activity during adolescence. Pediatrics 119, e314-e319.

38. Kimm SY, Glynn NW, Kriska AM et al. (2000) Longitudinal changes in physical activity in a biracial cohort during adolescence. Med Sci Sports Exerc 32, 1445-1454.

39. Dishman RK, Saunders RP, Motl RW et al. (2009) Selfefficacy moderates the relation between declines in physical activity and perceived social support in high school girls. J Pediatr Psychol 34, 441-451. 